Article

\title{
Cascade Cropping System with Horticultural and Ornamental Plants under Greenhouse Conditions
}

\author{
Pedro García-Caparrós ${ }^{1}$, Alfonso Llanderal ${ }^{1}$ (iD, Ivana Maksimovic ${ }^{2}$ (iD) and \\ María Teresa Lao ${ }^{1, *}$ \\ 1 Agronomy Department of Superior School Engineering, University of Almería, Agrifood Campus of \\ International Excellence ceiA3, Ctra. Sacramento s/n, La Cañada de San Urbano, 04120 Almería, Spain; \\ pedrogar123@hotmail.com (P.G.-C.); alfonsollanderal@hotmail.com (A.L.) \\ 2 Faculty of Agriculture, University of Novi Sad, Trg Dositeja Obradovića 8, 21000 Novi Sad, Serbia; \\ ivanam@polj.uns.ac.rs \\ * Correspondence: mtlao@ual.es; Tel.: +34-950-015-876; Fax: +34-950-015-939
}

Received: 29 December 2017; Accepted: 27 January 2018; Published: 30 January 2018

\begin{abstract}
The blending of drainage with water of low electrical conductivity and the sequential reuse of the drainage water are innovative technologies to manage salts in agricultural drainage. Plants of Cucumis melo were grown in coir grow bags, and Rosmarinus officinalis and Cacti spp. were grown in pots with a mixture of sphagnum peat-moss and perlite. In order to assess the effect and evolution over time of these water treatments on plant growth and water management and removal of nutrients, three water treatments were applied over a period of eight weeks. These were: (1) standard nutrient solution; (2) blended water treatment (drainage water blended with water of low electrical conductivity (EC)) and (3) sequential reuse of drainage water treatment. During the experimental growing period, samples of water supplies and drainages generated in each water treatment were collected weekly and from these data water volume and nutrient loads were calculated. At the end of the experiment, leaf fresh weight of rosemary plants decreased under the fertigation with the blended and sequential reuse water treatments. Nevertheless, the application of blended and sequentially reused water allowed for the saving of significant amounts of water and nutrients in comparison to the standard nutrient solution treatment. Considering these advantages, we strongly recommend the setting-up of these water treatments in areas with water scarcity such as in the Mediterranean Basin.
\end{abstract}

Keywords: blending water; Cucumis melo; drainage water; Rosmarinus officinalis; water footprint; water-sequential reuse

\section{Introduction}

The soilless surface in the Spanish Southeast consists of 5500 ha [1]. Nearly all soilless cropping systems in the greenhouses of this area are free-draining, also known as "open", systems that drain directly into the underlying soil [2,3]. As a consequence, this horticultural production system generates a high level of pollution in the environment due to the presence of high concentrations of nitrates and phosphorus in the drainages [4].

The establishment of closed hydroponic systems could be an advisable technique for growers in this area since it contributes to a reduction in water and fertilizer consumption [5]. Nevertheless, this technique is barely implemented mainly due to the investment costs and the frequent replenishment of recirculating nutrient solutions due to the salinity of the groundwater used for irrigation [6]. Moreover, the fear of disease and the risk of reduced yields is another disadvantage for the recycling of water and nutrients in greenhouse production [7].

As a consequence, the study of different management strategies of reusing the drainage water is required in order to reduce the pollution generated by the drainage water. Among these strategies 
are the sequential reuse or the blending of the drainage [8]. The sequential reuse of the drainage is based on the reuse of it to grow increasingly salt tolerant crops while concentrating the drainage to a manageable level. This treatment system is known as Serial Biological Concentration (SBC) [9]. Blending is based on the combination of two sources of irrigation water to produce irrigation water of suitable quality while increasing the overall irrigation water supply [10].

There are two groups of runoff water harvesting in farms such as rainwater harvesting and floodwater harvesting, which could be a useful tool to reuse the water in crop production, especially in dry areas, as have been reported by different researchers (Barron and Okwach [11]; Adekalu et al. [12]). The average precipitation in Almeria is approximately $250 \mathrm{~L} \mathrm{~m}^{-2}$ per year, and the rainfall is concentrated around a small number of events in the spring months, therefore the establishment of reservoir regulation becomes essential [13]. In Almería, 87.3\% of the greenhouses have artificial on-farm agricultural water reservoirs. These reservoirs can store rainwater falling on the roof of the greenhouses through the collection channels resulting in saving high quality water [14]. The use of this water harvesting technique also avoids the runoff in this production greenhouse area.

We investigated the potential for use of blending and sequential irrigation in a sequential production (horticultural and ornamental crops). The horticultural crop selected was Cucumis melo and the ornamental crop was Rosmarinus officinalis because both crops coincide in the crop cycle and as a consequence the drainage generated by the horticultural crop can be used to irrigate the ornamental crop. Although there are references about these fertigation techniques in a sequential production (Citrullus lanatus and Cordyline fruticosa) $[15,16]$, very little is known about the establishment of these techniques in other horticultural-ornamental crop systems. Therefore, in this study, a pot experiment with C. melo and R. officinalis was established in order to study the effects of different water treatments on plant growth, water saving and nutrient removal. We calculated a model that allows growers to determine the number of plants and the water supplies needed in each water system (horticultural and ornamental crops) from data on water uptake. The establishment of these water systems by growers would generate a water and nutrient saving with concomitant dual production (horticultural and ornamental crops). Moreover, it is necessary to point out that the cascade cropping system allows the pollutant runoff water harvesting making this system more sustainable from an environmental point of view.

\section{Materials and Methods}

\subsection{Experimental Design}

The present experiment was conducted at the facilities of the University of Almeria (Spain) in two contiguous greenhouses $\left(36^{\circ} 49^{\prime} \mathrm{N}, 2^{\circ} 24^{\prime} \mathrm{W}\right.$ ). Melon seedlings (cv. Abellan F1) were obtained from a local nursery and cultivated in a multitunnel greenhouse of $400 \mathrm{~m}^{2}$ into coir grow bag (Pelemix GB1002510 coir grow bag $(100 \cdot 25 \cdot 10 \mathrm{~cm}, \mathrm{~L} \cdot \mathrm{H} \cdot \mathrm{W}))$, with three plants per cultivation unit and a cultivation volume of $25 \mathrm{~L}$. The planting density was 1 plant per $\mathrm{m}^{2}$. The crop cycle lasted from 18 February to 20 May 2014 (91 days).

Rosemary seedlings were obtained from a local nursery and cultivated in a tunnel greenhouse of $150 \mathrm{~m}^{2}$. Seedlings were transplanted into $1.5 \mathrm{~L}$ polyethylene pots containing a mixture of sphagnum peat-moss and Perlite 80:20 $(v / v)$. The cultivation cycle lasted 8 weeks (from one month after sowing melon until the end of the melon cultivation cycle). The planting density was 12 plants per $\mathrm{m}^{2}$.

Cactus sp. were obtained from a local nursery and cultivated in the same greenhouse as rosemary seedlings. Cactus sp. were transplanted into a tray without holes and fertigated with drainages from rosemary plants in order to avoid the discharge of drainages to the environment. It is necessary to point out that this section of the experiment was considered as an experimental proof of the feasibility to grow Cactus with drainages from other crops since the arid climate in the Spanish Southeast allows an excellent growth of these species. Growth and morphology of Cactus sp. were observed, without further analyses. 
The microclimatic conditions inside the tunnel greenhouse during the experimental period, monitored continuously with HOBO SHUTTLE sensors (model H 08-004-02) showed a daily average temperature of $20.3 \pm 2.3^{\circ} \mathrm{C}$, relative humidity $(\mathrm{RH})$ of $64.3 \pm 3.5 \%$ and photosynthetically active radiation (PAR) of $90.5 \pm 9.1 \mu \mathrm{mol} \mathrm{m} \mathrm{m}^{-2} \mathrm{~s}^{-1}$.

\subsection{Experimental Water Treatments}

The experiment consisted of three different water treatments for rosemary seedlings: T0 (a standard nutrient solution proposed by Sonneveld and Straver [17] or control treatment), T1 (a sequential reuse treatment composed of raw drainages from C. melo) and T2 (a blended drainage treatment prepared by blending the raw drainages from $C$. melo with $50 \%$ of tap water). The tap water had the following composition: 1.1, 3.5, 2.0, 1.4 and $2.6 \mathrm{mmol} \mathrm{L}^{-1}$ of $\mathrm{S}, \mathrm{Cl}, \mathrm{Ca}, \mathrm{Mg}$ and $\mathrm{Na}$, respectively; and EC was $0.9 \mathrm{dS} \mathrm{m}^{-1}$ (Figure 1). The blending of drainage with high quality water also could be performed with the rainwater collected on the roof of the greenhouses being so more sustainable from an environmental point of view. The plants were irrigated manually every day. The volume of nutrient solution added to each pot during the experiment was $2.5 \mathrm{~L}$ for each treatment. The experimental design consisted of three fertigation treatments, four blocks and four plants (pots) per block giving a total of 48 plants of rosemary.

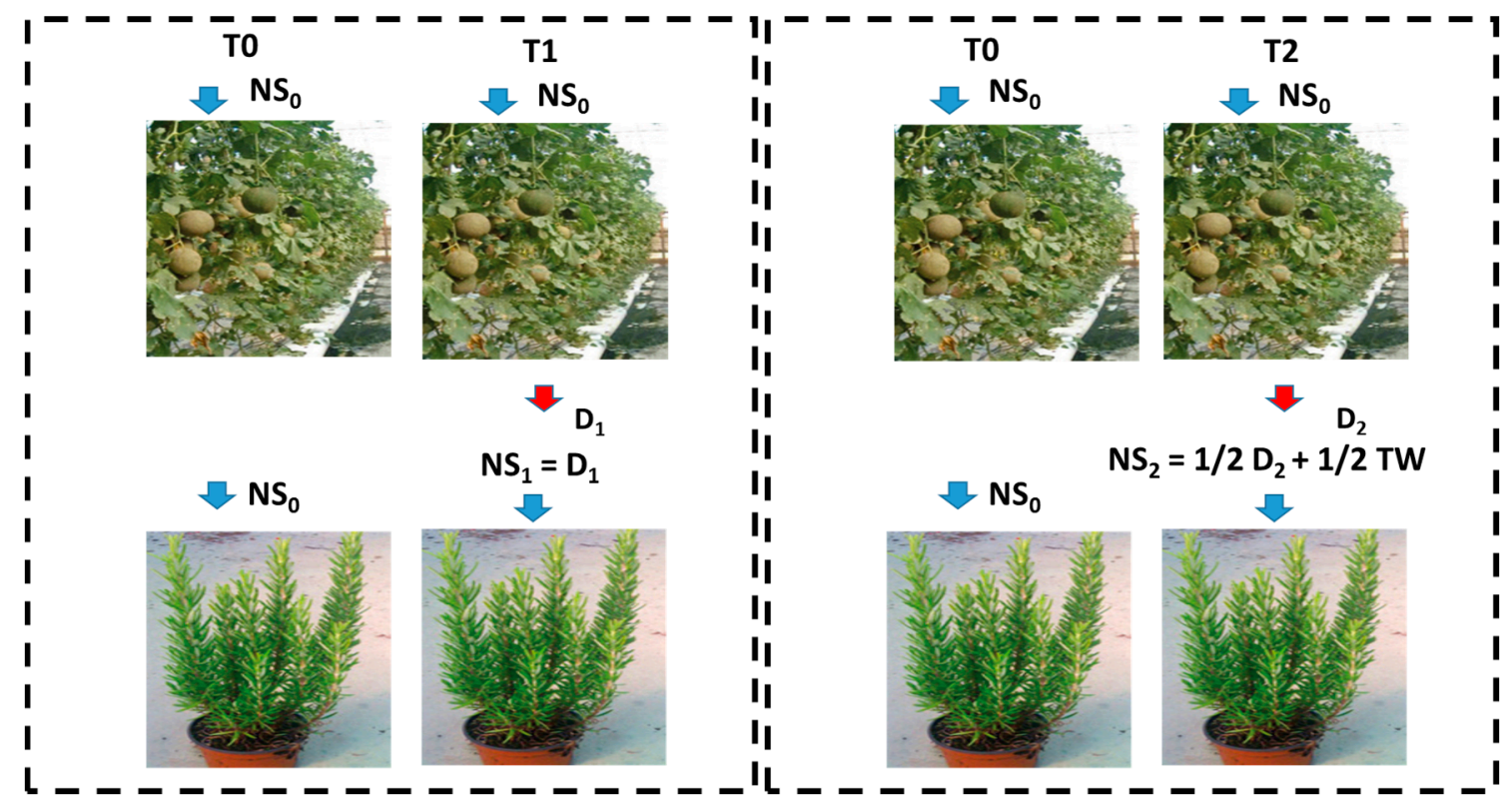

Figure 1. General layout of the different experimental water treatments in order to examine the effects of drainage water on growth and nutrient removal in a sequential production (horticultural and ornamental crops). $\mathrm{NS}_{0}$ : standard nutrient solution; $\mathrm{NS}_{1}$ : drainage from C. melo $\left(\mathrm{D}_{1}\right)$ fertigated with $\mathrm{NS}_{0}$ and $\mathrm{NS}_{2}$ : blend of tap water (TW) and drainage from irrigation of $C$. melo $\left(\mathrm{D}_{2}\right)$ fertigated with $\mathrm{NS}_{0}$. Vertical blue arrow represents the water treatment supplied in each species, vertical red arrow represents the drainage of previous crop that will be used in the following crop.

\subsection{Yield}

At the end of the experiment, eight cultivation units, each containing three melon plants, were randomly selected in the greenhouse and the fresh weight of marketable fruits of melon plants was recorded. Melon yield was expressed as grams of fresh weight per $\mathrm{m}^{2}$. Four rosemary plants per water treatment were collected to determine leaf fresh weight. In order to compare irrigation systems, rosemary yield was multiplied by the planting density (the same in all treatments with a value of 12 plants per $\mathrm{m}^{2}$ ) and distribution ratio of each system (with different values for T1 and T2 related to the differences of rosemary water uptake between irrigation systems). 


\subsection{Sample Collection and Characterization}

The samples of nutrient solution applied to melon were collected weekly at the entry point of the greenhouse by collecting water from four of the drippers used to irrigate melon. Drainages were collected randomly from four collection trays (one tray per two cultivation units). The buckets for collecting nutrient solutions and the trays for collecting drainage were covered with white polyethylene sheeting to reduce incoming radiation, thereby minimizing evaporation. Drainages from C. melo plants were collected weekly and then used to prepare fertigation treatments for rosemary plants. The drainage fraction obtained from melon production in our experiment was $28 \%$.

To determine the volume of drainage from water treatments of rosemary plants, four containers per treatment were randomly selected. The drainage of each container was collected weekly by placing a plastic collection bucket under each container. The buckets were tightly fitted to the containers to prevent evaporation of drainage between collection events and containers were also elevated to prevent them from sitting in the drainage.

Each sample of nutrient solution or drainage was composed by aliquots of $15 \mathrm{~mL}$, filtered through $0.45 \mu \mathrm{m}$ membrane filters and frozen until nutrient analyses were conducted. In each aliquot, nutrient concentration was determined by high-performance liquid chromatography (HPLC (883 Basic IC Plus, anions ion exchange column Metrosep A SUPP 4, cations ion exchange column Metrosep C4 100, IC conductivity detector $\left(0-15,000 \mu \mathrm{S} \cdot \mathrm{cm}^{-1}\right)$ Metrohm, Herisau, Switzerland)) as described by Csaky and Martinez-Grau [18].

Nutrient supplied and leached from each crop (expressed in grams) were calculated by multiplying concentrations of nutrients by the volume of nutrient solution supplied or the volume of drainage generated. Finally, in order to compare the volume of water (expressed in L) and nutrient loads (expressed in g) among water systems, the volume of water and nutrient loads of each water treatment were multiplied by planting density and distribution ratio of each water treatment, respectively.

\subsection{Water Footprint Systems}

In the determination of the water foot print of each water system, three components were calculated: blue water, grey water and green water (expressed in percentages). Blue water was calculated as the volume of water required for the production of each water system, grey water was calculated as the volume of freshwater required to assimilate the load of pollutants, that in our experiment is the threshold of $50 \mathrm{ppm}$ of $\mathrm{NO}_{3}{ }^{-}$established by the environmental guidelines and green water was the volume of rainwater consumed during the production (in greenhouses the value of green water was 0 ).

\subsection{Statistical Analysis}

The experiment was analysed as a completely randomized design. The Analyses of Variance (ANOVA) and the Fisher's Least significant difference (LSD) tests $(p<0.05)$ were used to assess the differences between water treatments. All statistical analyses were performed using Statgraphics Centurion XVI.II (Statpoint Technologies, Inc., Warrenton, VA, USA). Previously, normality was verified using the Shapiro-Wilk test, and homogeneity of variance was tested using the Bartlett test. Differences were considered significant at $p<0.05$.

\section{Results}

\subsection{Modelling of Water Consumption}

The aim of this trial was to calculate the number of plants needed in each water system through the use of a series of inputs according to the model proposed by García-Caparrós et al. [19], in order to reduce the volume of water and nutrients used in the fertigation of a dual production system: horticultural and ornamental crops. 
Finally, with the values obtained using equations, we determined the distribution ratio (DR) of each species (expressed in number of plants per $\mathrm{m}^{2}$ ) that can be grown in each water system. The values of DR in T1 was 1/0.25 and in T2 was 1/0.50 which were also applied to T0 in order to compare the data obtained between water systems.

\subsection{Chemical Composition of Water Treatments}

The average chemical composition of the three water treatments supplied to rosemary plants is summarized in Table 1 . The irrigation with the sequential reuse and blended water treatments (T1 and $\mathrm{T} 2$ ) showed higher $\mathrm{pH}$ compared to the control or nutrient solution (T0). The irrigation with the sequential reuse and blended water treatments (T1 and T2) showed lower concentrations of $\mathrm{NO}_{3}{ }^{-}$, $\mathrm{PO}_{4}{ }^{3-}$ and $\mathrm{K}^{+}$compared to the control (T0). The treatment $\mathrm{T} 1$ showed the greatest concentration of $\mathrm{Cl}^{-}, \mathrm{SO}_{4}{ }^{2-}, \mathrm{Ca}^{2+}, \mathrm{Mg}^{2+}$ and $\mathrm{Na}^{+}$and the highest $\mathrm{EC}$.

Table 1. Chemical composition of water applied in each water treatment. EC (electrical conductivity) was expressed in $\mathrm{dS} \mathrm{m} \mathrm{m}^{-1}$ and nutrient concentration in $\mathrm{mmol} \mathrm{L}^{-1}$. Water $\mathrm{NS}_{0}$ : standard nutrient solution; $\mathrm{NS}_{1}$ : drainage from irrigation of $C$. melo $\left(\mathrm{D}_{1}\right)$ fertigated with $\mathrm{NS}_{0}$ and $\mathrm{NS}_{2}$ : blend of tap water and drainage from irrigation of C. melo $\left(\mathrm{D}_{2}\right)$ fertigated with $\mathrm{NS}_{0}$. Data are the means \pm standard deviation of four samples per treatment. For $\mathrm{NS}_{1}$ and $\mathrm{NS}_{2}$, the average values of the different chemical parameters analyzed weekly during the trial are given. Averages within a file with the same letters are not significantly different at $p<0.05$ (ANOVA and LSD test).

\begin{tabular}{cccc}
\hline Parameters & NS $_{\mathbf{0}}$ & $\mathbf{N S}_{\mathbf{1}}$ & $\mathbf{N S}_{\mathbf{2}}$ \\
\hline $\mathrm{pH}$ & $5.8 \pm 0.1 \mathrm{~b}$ & $6.6 \pm 0.4 \mathrm{a}$ & $6.6 \pm 0.2 \mathrm{a}$ \\
$\mathrm{EC}$ & $2.0 \pm 0.1 \mathrm{~b}$ & $3.03 \pm 0.2 \mathrm{a}$ & $2.2 \pm 0.2 \mathrm{~b}$ \\
$\mathrm{NO}_{3}{ }^{-}$ & $623.1 \pm 57.8 \mathrm{a}$ & $297.6 \pm 29.1 \mathrm{~b}$ & $148.8 \pm 15.4 \mathrm{c}$ \\
$\mathrm{H}_{2} \mathrm{PO}_{4}^{-}$ & $140.6 \pm 4.8 \mathrm{a}$ & $1.9 \pm 0.1 \mathrm{~b}$ & $1.8 \pm 0.1 \mathrm{~b}$ \\
$\mathrm{Cl}^{-}$ & $122.4 \pm 3.9 \mathrm{c}$ & $628.7 \pm 54.9 \mathrm{a}$ & $505.4 \pm 51.4 \mathrm{~b}$ \\
$\mathrm{SO}_{4}^{2-}$ & $215.0 \pm 8.6 \mathrm{~b}$ & $392.6 \pm 40.3 \mathrm{a}$ & $238.0 \pm 21.1 \mathrm{~b}$ \\
$\mathrm{Ca}^{2+}$ & $202.1 \pm 10.2 \mathrm{~b}$ & $345.6 \pm 31.1 \mathrm{a}$ & $225.3 \pm 21.5 \mathrm{~b}$ \\
$\mathrm{Mg}^{2+}$ & $37.4 \pm 1.9 \mathrm{c}$ & $93.3 \pm 8.2 \mathrm{a}$ & $74.1 \pm 6.5 \mathrm{~b}$ \\
$\mathrm{~K}^{+}$ & $186.4 \pm 8.2 \mathrm{a}$ & $129.4 \pm 10.1 \mathrm{~b}$ & $75.2 \pm 7.0 \mathrm{c}$ \\
$\mathrm{Na}^{+}$ & $59.8 \pm 4.1 \mathrm{c}$ & $137.3 \pm 10.5 \mathrm{a}$ & $116.1 \pm 9.2 \mathrm{~b}$ \\
\hline
\end{tabular}

\subsection{Yield}

Melon yield showed no variation between treatments with a mean value of $5500 \mathrm{~g}$ per $\mathrm{m}^{2}$, since the yield was the same in all treatments because of it was the first stage to obtain drainages for the irrigation of rosemary plants. In rosemary plants, the fertigation with T1 and T2 resulted in a yield decrease of $22 \%$ and $36 \%$ respectively, compared to the control (T0) (Table 2).

Table 2. Cucumis melo yield (expressed as grams of fruit fresh weight per $\mathrm{m}^{2}$ ) and R. officinalis yield (expressed as grams of leaf fresh weight per $\mathrm{m}^{2}$ ). Averages within a file with the same letters are not significantly different at $p<0.05$ (ANOVA and LSD test).

\begin{tabular}{cccccc}
\hline Crops & T0 & T1 & & T0 & T2 \\
\hline C. melo & $5500 \mathrm{a}$ & $5500 \mathrm{a}$ & C. melo & $5500 \mathrm{a}$ & $5500 \mathrm{a}$ \\
R. officinalis & $35.15 \pm 3.73 \mathrm{a}$ & $27.57 \pm 2.45 \mathrm{~b}$ & R. officinalis & $70.30 \pm 7.40 \mathrm{a}$ & $44.65 \pm 4.15 \mathrm{~b}$ \\
\hline
\end{tabular}

\subsection{Development of a Model of Water Consumption}

Concerning water volume and nutrient loads of each water system, the water system T1 resulted in $18 \%$ of saved water compared to T0 $(33.4 \mathrm{~L}$ in $\mathrm{T} 0$ and $27.3 \mathrm{~L}$ in $\mathrm{T} 1)$ and the same volume of drainage generated in both systems $(7.8 \mathrm{~L})$. The anion loads in the drainage water were also calculated; comparing $\mathrm{T} 1$ against $\mathrm{T} 0$, there was an increase of $8 \%{\text { in } \mathrm{Cl}^{-}}^{-} \mathrm{T} 0(4.7 \mathrm{~g})$ and $\left.\mathrm{T} 1(5.1 \mathrm{~g})\right)$ and $27 \%$ in 
$\mathrm{SO}_{4}{ }^{2-}$ (T0 (1.8 g) and T1 (2.3 g)), a removal of 35\% of $\mathrm{NO}_{3}{ }^{-}$(T0 (3.7 g) and $\left.\mathrm{T} 1(2.4 \mathrm{~g})\right)$ and no varations in $\mathrm{H}_{2} \mathrm{PO}_{4}{ }^{-}$concentration. Concerning cation loads, there was a removal of $18 \%$ of $\mathrm{Ca}^{2+}(\mathrm{T} 0(5.1 \mathrm{~g})$ and $\mathrm{T} 1(4.2 \mathrm{~g})$ ) and no variations in $\mathrm{Na}^{+}, \mathrm{K}^{+}$and $\mathrm{Mg}^{2+}$ concentration (Table 3).

Table 3. Water volume (expressed in L) and nutrients (expressed in g) applied and leached in T0: standard nutrient solution and $\mathrm{T} 1$ : sequential reuse treatment. $\mathrm{C}=C$. melo, $\mathrm{R}=\mathrm{R}$. officinalis and $\mathrm{T}=\mathrm{C}+\mathrm{R}$.

\begin{tabular}{|c|c|c|c|c|c|c|c|c|c|c|c|c|}
\hline \multirow{3}{*}{ Parameter } & \multicolumn{6}{|c|}{ T0 } & \multicolumn{6}{|c|}{ T1 } \\
\hline & \multicolumn{3}{|c|}{ Applied } & \multicolumn{3}{|c|}{ Leached } & \multicolumn{3}{|c|}{ Applied } & \multicolumn{3}{|c|}{ Leached } \\
\hline & C & $\mathbf{R}$ & $\mathbf{T}$ & C & $\mathbf{R}$ & $\mathrm{T}$ & $\mathrm{C}$ & $\mathbf{R}$ & $\mathbf{T}$ & $\mathrm{C}$ & $\mathbf{R}$ & $\mathrm{T}$ \\
\hline Water & 27.3 & 6.1 & 33.4 & 6.3 & 1.5 & 7.8 & 27.3 & $* * *$ & 27.3 & 6.3 & 1.5 & 7.8 \\
\hline $\mathrm{Cl}^{-}$ & 3.3 & 0.9 & 4.2 & 3.7 & 1.0 & 4.7 & 3.3 & 4.7 & 8.0 & 3.7 & 1.4 & 5.1 \\
\hline $\mathrm{NO}_{3}^{-}$ & 16.1 & 4.6 & 20.7 & 2.3 & 1.3 & 3.7 & 16.1 & 2.2 & 18.3 & 2.3 & 0.1 & 2.4 \\
\hline $\mathrm{H}_{2} \mathrm{PO}_{4}^{-}$ & 3.7 & 1.1 & 4.8 & 0.5 & 0.1 & 0.6 & 3.7 & 0.6 & 4.3 & 0.5 & 0.1 & 0.6 \\
\hline $\mathrm{SO}_{4}^{2-}$ & 5.8 & 1.7 & 7.5 & 1.3 & 0.5 & 1.8 & 5.8 & 2.9 & 8.7 & 1.3 & 1.0 & 2.3 \\
\hline $\mathrm{Na}^{+}$ & 1.6 & 0.5 & 2.1 & 1.6 & 0.5 & 2.1 & 1.6 & 1.0 & 2.6 & 1.6 & 0.5 & 2.1 \\
\hline $\mathrm{K}^{+}$ & 5.2 & 1.5 & 6.7 & 0.6 & 0.3 & 0.9 & 5.2 & 1.0 & 6.2 & 0.6 & 0.3 & 0.9 \\
\hline $\mathrm{Ca}^{2+}$ & 5.6 & 1.6 & 7.2 & 3.6 & 1.5 & 5.1 & 5.6 & 2.6 & 8.2 & 3.6 & 0.6 & 4.2 \\
\hline $\mathrm{Mg}^{2+}$ & 1.0 & 0.3 & 1.3 & 0.9 & 0.2 & 1.1 & 1.0 & 0.7 & 1.7 & 0.9 & 0.2 & 1.1 \\
\hline
\end{tabular}

Note: ${ }^{* * *}$ the volume of water applied is not tabulated since it belongs to the volume of drainage generated by C. melo.

There was a water savings of $18 \%$ in T2 compared to $\mathrm{T} 0(39.6 \mathrm{~L}$ in $\mathrm{T} 0$ and $33.4 \mathrm{~L}$ in $\mathrm{T} 2)$ and the same volume of drainage was generated in both systems $(9.2 \mathrm{~L})$. In the case of anion loads, there was an increase of $11 \%$ in $\mathrm{Cl}^{-}(\mathrm{T} 0(5.6 \mathrm{~g})$ and $\mathrm{T} 2(6.1 \mathrm{~g}))$ and $39 \%$ in $\mathrm{SO}_{4}{ }^{2-}$ (T0 (2.3 g) and $\left.\mathrm{T} 2(3.2 \mathrm{~g})\right)$, a removal of $49 \%$ of $\mathrm{NO}_{3}{ }^{-}$(T0 ( $\left.4.9 \mathrm{~g}\right)$ and $\mathrm{T} 2(2.5 \mathrm{~g})$ ) and no variations in $\mathrm{H}_{2} \mathrm{PO}_{4}{ }^{-}$concentration. Concerning cation loads, there was a removal of $25 \%$ in $\mathrm{K}^{+}$(T0 (1.2 g) and T2 $\left.(0.9 \mathrm{~g})\right)$, of $34 \%$ in $\mathrm{Ca}^{2+}(\mathrm{T} 0(6.7 \mathrm{~g})$ and T2 $(4.4 \mathrm{~g}))$ and 21\% in $\mathrm{Mg}^{2+}(\mathrm{T} 0(1.4 \mathrm{~g})$ and $\mathrm{T} 2(1.1 \mathrm{~g}))$ and no variations in $\mathrm{Na}^{+}$concentration (Table 4).

Table 4. Water volume (expressed in L) and nutrients (expressed in g) applied and leached in T0: standard nutrient solution and T2: blended drainage treatment. $\mathrm{C}=\mathrm{C}$. melo, $\mathrm{R}=\mathrm{R}$. officinalis and $\mathrm{T}=\mathrm{C}+\mathrm{R}$.

\begin{tabular}{|c|c|c|c|c|c|c|c|c|c|c|c|c|}
\hline \multirow{3}{*}{ Parameter } & \multicolumn{6}{|c|}{ T0 } & \multicolumn{6}{|c|}{$\mathrm{T} 2$} \\
\hline & \multicolumn{3}{|c|}{ Applied } & \multicolumn{3}{|c|}{ Leached } & \multicolumn{3}{|c|}{ Applied } & \multicolumn{3}{|c|}{ Leached } \\
\hline & C & $\mathbf{R}$ & $\mathrm{T}$ & C & $\mathbf{R}$ & $\mathrm{T}$ & C & $\mathbf{R}$ & $\mathrm{T}$ & C & $\mathbf{R}$ & $T$ \\
\hline Water & 27.3 & 12.3 & 39.6 & 6.3 & 2.9 & 9.2 & 27.3 & 6.2 & 33.4 & 6.3 & 2.9 & 9.2 \\
\hline $\mathrm{Cl}^{-}$ & 3.3 & 1.9 & 5.2 & 3.7 & 1.9 & 5.6 & 3.3 & 8.1 & 11.4 & 3.7 & 2.4 & 6.1 \\
\hline $\mathrm{NO}_{3}^{-}$ & 16.1 & 9.1 & 25.2 & 2.3 & 2.6 & 4.9 & 16.1 & 2.2 & 18.3 & 2.3 & 0.2 & 2.5 \\
\hline $\mathrm{H}_{2} \mathrm{PO}_{4}^{-}$ & 3.7 & 2.1 & 5.8 & 0.5 & 0.1 & 0.6 & 3.7 & 0.8 & 4.5 & 0.5 & 0.1 & 0.6 \\
\hline $\mathrm{SO}_{4}{ }^{2-}$ & 5.8 & 3.3 & 9.1 & 1.3 & 1.0 & 2.3 & 5.8 & 3.5 & 9.3 & 1.3 & 1.9 & 3.2 \\
\hline $\mathrm{Na}^{+}$ & 1.6 & 0.9 & 2.5 & 1.6 & 0.8 & 2.4 & 1.6 & 2.0 & 3.6 & 1.6 & 0.8 & 2.4 \\
\hline $\mathrm{K}^{+}$ & 5.2 & 2.9 & 8.1 & 0.6 & 0.6 & 1.2 & 5.2 & 1.1 & 6.2 & 0.6 & 0.3 & 0.9 \\
\hline $\mathrm{Ca}^{2+}$ & 5.6 & 3.2 & 8.8 & 3.6 & 3.1 & 6.7 & 5.6 & 3.6 & 9.2 & 3.6 & 0.8 & 4.4 \\
\hline $\mathrm{Mg}^{2+}$ & 1.0 & 0.6 & 1.6 & 0.9 & 0.5 & 1.4 & 1.0 & 1.1 & 2.1 & 0.9 & 0.2 & 1.1 \\
\hline
\end{tabular}

\subsection{Water Footprint}

Comparing the water footprints of the water systems, there was a reduction of $2 \%$ in blue water between $\mathrm{T} 0$ and $\mathrm{T} 1$ and there was an increase of $4 \%$ in blue water between $\mathrm{T} 0$ and $\mathrm{T} 2$ (Figure 2). The different values of $\mathrm{T} 0$ are related to the respective distribution ratio calculated in each system. 


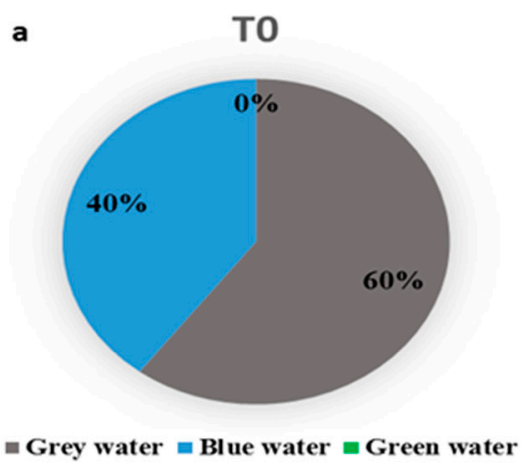

b

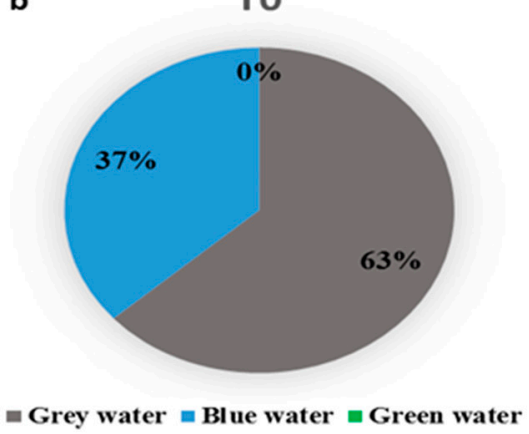

T1

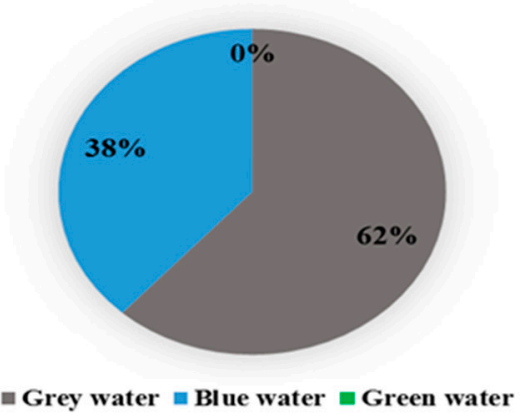

T2

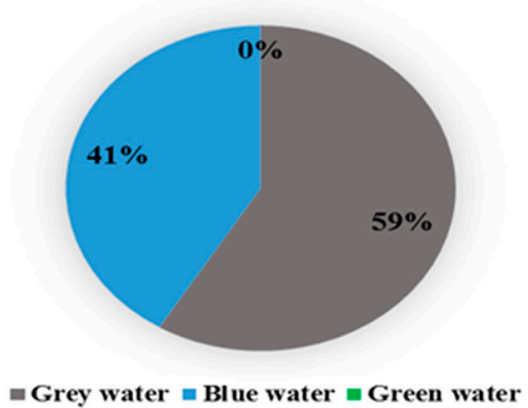

Figure 2. Water footprint of each water system itemized by grey, blue and green water components (a) (T0 against T1) and (b) (T0 against T2).

\section{Discussion}

The $28 \%$ leachate fraction of melon, obtained in our experiment, was in line with the findings reported by Rodriguez et al. [20] who found that the leachate fraction of melon ranged from 25 to $30 \%$ in soilless systems in Spanish Southeast. In addition, total fruit production of melon recorded in our experiment $\left(5.5 \mathrm{~kg} \mathrm{~m}^{-2}\right)$ was similar to yield production reported by other researchers such as Contreras et al. [21] and Martínez et al. [22] under the same type of cropping system.

The irrigation with sequential reuse and blended drainage water treatments resulted in a reduction of leaf fresh weight in rosemary plants compared to the irrigation with a standard nutrient solution. Lower concentrations of N, P and K in T1 and T2, which are essential for plant growth, can be the main reason for yield reduction as was also reported by Sardans et al. [23] in an experiment conducted with rosemary plants subjected to different water and nutrients treatments.

The increase of EC in the sequential reuse and blended drainage water treatments compared to the original nutrient solution could be due to the increase of $\mathrm{Na}^{+}, \mathrm{Cl}^{-}, \mathrm{SO}_{4}{ }^{2-}, \mathrm{Mg}^{2+}$ and $\mathrm{Ca}^{2+}$ concentrations caused primarily by the concentrating effects of plant water uptake as reported by Massa et al. [24]. Concerning $\mathrm{pH}$, a higher value in the sequential reuse and blended drainage water treatments can be related to the nitrate uptake by melon plants and the consequent release of $\mathrm{H}^{+}$[25]. Moreover, the reduction in $\mathrm{NO}_{3}{ }^{-}, \mathrm{H}_{2} \mathrm{PO}_{4}{ }^{-}$and $\mathrm{K}^{+}$concentrations in the drainage waters applied for irrigation compared to the nutrient solution could be related to the melon nutrient uptake. Our results were similar with the findings reported by Neocleous and Savvas [26] in the same crop.

The irrigation with sequential reuse water against standard nutrient solution resulted in an increase of grey water which may be dangerous from an environmental point of view as suggested by Castellanos et al. [27], while the irrigation with blended drainage water against standard nutrient solution resulted in an increase of blue water which is a great drawback in areas with water scarcity as mentioned also by Hoekstra et al. [28].

The comparison between water systems, sequential reuse and blended drainage water treatments, against a standard nutrient solution treatment, reveals saving of water and removal of nutrients. The 
reduction of the water volume recorded in these closed systems is a great advantage, particularly in areas with scarcity of water such as in the Mediterranean area [29]. Significant removal of $\mathrm{NO}_{3}{ }^{-}$in applied water treatments can be related to the more intensive growth of these crops which resulted in a higher uptake of $\mathrm{N}$ as reported also by Vymazal [30]. Moreover, the removal of $\mathrm{NO}_{3}{ }^{-}$is an additional benefit, especially in the Spanish Southeast, since it is an area classified as a nitrate vulnerable zone in accordance with the European Union Directive [31]. The percentages of nutrient removal in these water systems were lower than in the other systems such as the soil treatment $[32,33]$ or the biofiltration systems [34], where the percentages of nutrient removal were higher than $50 \%$, pointing out that the results obtained in such different environmental conditions are not directly comparable.

\section{Conclusions}

Although the irrigation in sequential reuse and with blended drainage water resulted in a yield decrease of rosemary plants (acceptable from marketing point of view) compared to the standard nutrient solution treatment, the establishment of these irrigation systems resulted in a saving of water and removal of nitrates, which is a great advantage, since the Spanish Southeast is an area with water scarcity which is also classified as a nitrate vulnerable zone. Finally, we encourage growers to use the equations defined in this experiment for the design and setting-up of dual system production (horticultural and ornamental crops) to reduce the volume of water supplies and the environmental pollution caused by nitrates.

Author Contributions: The authors contributed equally to this work.

Conflicts of Interest: The authors declare no conflict of interest.

\section{Abbreviations}

The following abbreviations are used in this manuscript:

$\begin{array}{ll}\text { DR } & \text { Distribution ratio } \\ \text { EC } & \text { Electrical conductivity } \\ \text { HPLC } & \text { High-performance liquid chromatography } \\ \text { PAR } & \text { Photosynthetically active radiation } \\ \text { RH } & \text { Relative humidity } \\ \text { SBC } & \text { Serial Biological Concentration }\end{array}$

\section{References}

1. Urrestarazu, M. State of the art and new trends of soilless culture in Spain and in emerging countries. Acta Hortic. 2013, 1013, 305-312. [CrossRef]

2. Pardossi, A.; Tognoni, F.; Incrocci, L. Mediterranean greenhouse technology. Chron. Hortic. 2004, 44, $28-34$.

3. Thompson, R.B.; Gallardo, M.; Rodríguez, J.S.; Sánchez, J.A.; Magán, J.J. Effect of N uptake concentration on nitrate leaching from tomato grown in free-draining soilless culture under Mediterranean conditions. Sci. Hortic. Amst. 2013, 150, 387-398. [CrossRef]

4. Granados, M.R.; Thompson, R.B.; Fernández, M.D.; Martínez-Gaitán, C.; Gallardo, M. Prescriptive corrective nitrogen and irrigation management of fertigated and drip-irrigated vegetable crops using modelling and monitoring approaches. Agric. Water Manag. 2013, 119, 121-134. [CrossRef]

5. Carmassi, G.; Incrocci, L.; Maggini, R.; Malorgio, F.; Tognoni, F.; Pardossi, A. Modelling salinity build-up in recirculating nutrient solution culture. J. Plant Nutr. 2005, 28, 431-445. [CrossRef]

6. Magan, J.J.; Gallardo, M.; Thompson, R.B.; Lorenzo, P. Effects of salinity on fruit yield and quality of tomato grown in soil-less culture in green-houses in Mediterranean climatic conditions. Agric. Water Manag. 2008, 95, 1041-1055. [CrossRef]

7. Grewal, H.S.; Maheshwari, B.; Parks, S.E. Water and nutrient use efficiency of a low-cost hydroponic greenhouse for a cucumber crop: An Australian case study. Agric. Water Manag. 2011, 98, 841-846. [CrossRef] 
8. Grattan, S.R.; Oster, J.D.; Benes, S.E.; Kaffka, S.R. Use of saline drainage waters for irrigation. In Agricultural Salinity Assessment and Management, 2nd ed.; Wallender, W.W., Tanji, K.K., Eds.; ASCE Manuals and Reports on Engineering Practice 71; ASCE: Reston, VA, USA, 2012; pp. 687-719.

9. Bethune, M.G.; Gyles, O.A.; Wang, Q.J. Options for management of saline ground water in an irrigated farming system. Aust. J. Exp. Agric. 2004, 44, 181-188. [CrossRef]

10. Grattan, S.R.; Oster, J.D. Use and reuse of saline-sodic waters for irrigation of crops. In Crop Production in Saline Environments: Global and Integrative Perspectives; Goyal, S.S., Sharma, S.K., Rains, D.W., Eds.; Haworth Press: New York, NY, USA, 2003; pp. 131-162.

11. Barron, J.; Okwach, G. Run-off water harvesting for dry spell mitigation in maize (Zea mays L.): Results from on-farm research in semi-arid Kenya. Agric. Water. Manag. 2005, 74, 1-21. [CrossRef]

12. Adekalu, K.O.; Balogun, J.A.; Aluko, O.B.; Okunade, D.A.; Gowing, J.W.; Faborode, M.O. Runoff water harvesting for dry spell mitigation for cowpea in the savannah belt of Nigeria. Agric. Water. Manag. 2009, 96, 1502-1508. [CrossRef]

13. Carvajal, F.; Agüera, F.; Sánchez-Hermosilla, J. Water balance in artificial on-farm agricultural water reservoirs for the irrigation of intensive greenhouse crops. Agric. Water. Manag. 2014, 131, 146-155. [CrossRef]

14. García-García, M.C.; Céspedes, A.J.; Lorenzo, P.; Pérez-Parra, J.J.; Escudero, M.C.; Sánchez-Guerrero, M.C.; Medrano, E.; Baeza, E.; López, J.C.; Magán, J.J.; et al. El Sistema de Producción Hortícola de la Provincia de Almería; IFAPA (Instituto de Formación Agraria y Pesquera de Andalucía): Huelva, Spain, 2016; 179p.

15. Plaza, B.M.; Soriano, F.; Jiménez-Becker, S.; Lao, M.T. Nutritional responses of Cordyline fruticosa var. 'Red Edge' to fertigation with leachates vs. conventional fertigation: Chloride, nitrogen, phosphorus and sulphate. Agric. Water Manag. 2016, 173, 61-66. [CrossRef]

16. Plaza, B.M.; Paniagua, F.; Ruiz, M.R.; Jiménez-Becker, S.; Lao, M.T. Nutritional responses of Cordyline fruticosa var. 'Red Edge' to fertigation with leachates vs. conventional fertigation: Sodium, potassium, calcium and magnesium. Sci. Hortic. Amst. 2017, 215, 157-163. [CrossRef]

17. Sonneveld, C.; Straver, N. Voedingsoplossingen voor Groenten en Bloemengeteeld in Water of Substraten (Nutrient Solutions for Vegetables and Flower Grown in Water or Substrates), 10th ed. 1994. Available online: http:/ / edepot.wur.nl/237302 (accessed on 1 October 2017).

18. Csáky, A.; Martínez-Grau, M.A. Técnicas Experimentales en Síntesis Orgánica; Ed. Síntesis: Madrid, Spain, 1998.

19. Garcia-Caparrós, P.; Llanderal, A.; El-Tarawy, A.; Maksimovic, I.; Lao, M.T. Crop and irrigation management systems under greenhouse conditions. Water 2018, 10, 62. [CrossRef]

20. Rodríguez, D.; Reca, J.; Martínez, J.; Lao, M.T.; Urrestarazu, M. Effect of controlling the leaching fraction on the fertigation and production of a tomato crop under soilless culture. Sci. Hortic. Amst. 2014, 179, 153-157. [CrossRef]

21. Contreras, J.I.; Plaza, B.M.; Lao, M.T.; Segura, M.L. Growth and nutritional response of melon to water quality and nitrogen potassium fertigation levels under greenhouse Mediterranean conditions. Commun. Soil Sci. Plant Anal. 2012, 43, 434-444. [CrossRef]

22. Martínez, S.; Suay, R.; Moreno, J.; Segura, M.L. Reuse of tertiary municipal wastewater effluent for irrigation of Cucumis melo L. Irrig. Sci. 2013, 31, 661-672. [CrossRef]

23. Sardans, J.; Rodà, F.; Peñuelas, J. Effects of water and a nutrient pulse supply on Rosmarinus officinalis growth, nutrient content and flowering in the field. Environ. Exp. Bot. 2005, 53, 1-11. [CrossRef]

24. Massa, D.; Incrocci, L.; Maggini, R.; Carmassi, G.; Campiotti, C.A.; Pardossi, A. Strategies to decrease water drainage and nitrate emission from soilless cultures of greenhouse tomato. Agric. Water Manag. 2010, 97, 971-980. [CrossRef]

25. Marschner, H. Mineral Nutrition of Higher Plants; Academic Press: Cambridge, MA, USA, 2011; 672p.

26. Neocleous, D.; Savvas, D. Effect of different macronutrient cation ratios on macronutrient and water uptake by melon (Cucumis melo) grown in recirculating nutrient solution. J. Plant Nutr. Soil Sci. 2015, 178, 320-332. [CrossRef]

27. Castellanos, M.T.; Cartagena, M.C.; Requejo, M.I.; Arce, A.; Cabello, M.J.; Ribas, F.; Tarquis, A.M. Agronomic concepts in water footprint assessment: A case of study in a fertirrigated melon crop under semiarid conditions. Agric. Water Manag. 2016, 170, 81-90. [CrossRef]

28. Hoekstra, A.Y.; Mekonnen, M.M.; Chapagain, A.K.; Mathews, R.E.; Richter, B.D. Global monthly water scarcity: Blue water footprints versus blue water availability. PLoS ONE 2012, 7, e32688. [CrossRef] [PubMed] 
29. García-Caparrós, P.; Llanderal, A.; Pestana, M.; Correia, P.; Lao, M.T. Tolerance mechanisms of three potted ornamental plants grown under moderate salinity. Sci. Hortic. Amst. 2016, 201, 84-91. [CrossRef]

30. Vymazal, J. Removal of nutrients in various types of constructed wetlands. Sci. Total. Environ. 2007, 380, 48-65. [CrossRef] [PubMed]

31. García-Caparrós, P.; Contreras, J.I.; Baeza, R.; Segura, M.L.; Lao, M.T. Integral management of irrigation water in intensive horticultural systems of Almería. Sustainability 2017, 9, 2271. [CrossRef]

32. Zhao, J.F.; Ma, X.L.; Jin, L.M. Improved land-treatment-system with slow rate for sewage and its test. Trans. CSAE 2006, 22, 85-88.

33. Duan, J.; Geng, C.; Li, X.; Duan, Z.; Yang, L. The treatment performance and nutrient removal of a garden land infiltration system receiving dairy farm wastewater. Agric. Water Manag. 2015, 150, 103-110. [CrossRef]

34. Szota, C.; Farrell, C.; Livesley, S.J.; Fletcher, T.D. Salt tolerant plants increase nitrogen removal from biofiltration systems affected by saline stormwater. Water Res. 2015, 83, 195-204. [CrossRef] [PubMed]

(C) 2018 by the authors. Licensee MDPI, Basel, Switzerland. This article is an open access article distributed under the terms and conditions of the Creative Commons Attribution (CC BY) license (http://creativecommons.org/licenses/by/4.0/). 